\title{
X-ray computed tomography investigation of structures in Opalinus Clay from large-scale to small-scale after mechanical testing
}

\author{
Annette Kaufhold ${ }^{1,2}$, Matthias Halisch ${ }^{3}$, Gerhard Zacher ${ }^{4}$, and Stephan Kaufhold ${ }^{1}$ \\ ${ }^{1}$ Federal Institute for Geosciences and Natural Resources (BGR), Stilleweg 2, 30655 Hanover, Germany \\ ${ }^{2}$ Federal Office for Radiation Protection (BFS), Willy-Brandt-Straße 5, 38226 Salzgitter, Germany \\ ${ }^{3}$ Leibniz Institute for Applied Geophysics (LIAG), Stilleweg 2, 30655 Hanover, Germany \\ ${ }^{4}$ GE Sensing \& Inspection Technologies GmbH, Niels-Bohr-Straße 7, 31515 Wunstorf, Germany
}

Correspondence to: Matthias Halisch (matthias.halisch@liag-hannover.de)

Received: 29 February 2016 - Published in Solid Earth Discuss.: 9 March 2016

Revised: 1 June 2016 - Accepted: 11 July 2016 - Published: 3 August 2016

\begin{abstract}
In the past years X-ray computed tomography (CT) has became more and more common for geoscientific applications and is used from the $\mu \mathrm{m}$-scale (e.g. for investigations of microfossils or pore-scale structures) up to the dm-scale (full drill cores or soil columns). In this paper we present results from $\mathrm{CT}$ imaging and mineralogical investigations of an Opalinus Clay core on different scales and different regions of interest, emphasizing especially the 3$\mathrm{D}$ evaluation and distribution of cracks and their impact on mechanical testing of such material. Enhanced knowledge of the testing behaviour of the Opalinus Clay is of great interest, especially since this material is considered for a long-term radioactive waste disposal and storage facility in Switzerland. Hence, results are compared regarding the mineral (i.e. phase) contrast resolution, the spatial resolution, and the overall scanning speed.

With this extensive interdisciplinary scale-down approach it has been possible to characterize the general fracture propagation in comparison to mineralogical and textural features of the Opalinus Clay. Additionally, and as far as we know, a so-called mylonitic zone, located at an intersect of two main fractures, has been observed for the first time for an experimentally deformed Opalinus sample. The multi-scale results are in good accordance to data from naturally deformed Opalinus Clay samples, which enables us to perform systematical research under controlled laboratory conditions. Accompanying 3-D imaging greatly enhances the capability of data interpretation and assessment of such a material.
\end{abstract}

\section{Introduction}

In the past years X-ray computed tomography (CT) has became more and more common for geoscientific applications and is used from the $\mu \mathrm{m}$-scale (e.g. for investigations of microfossils or pore-scale structures; e.g. Schmitt et al., 2016) up to the dm-scale (full drill cores or soil columns; e.g. Schlüter et al., 2015). Consequently, benchtop CT equipment for material and geoscience were developed and are now frequently used because almost all geoscientific samples show 3-D features which would be missed when analysing 2-D sections only (e.g. by classical microscopy). These features are for example the abundance of minerals, the location of particular particles towards bedding (or texture in general), the pore system, cracks, and veins. The 3-D distribution of all these features can be extracted and used for a variety of numerical modelling purposes (Andrä et al., 2013). However, due to the resolution of $\mu$-CT devices in range of a few $\mu \mathrm{m}$ (Brunke et al., 2008), it is particularly suitable to study sandstones, soils, or other rocks with large particles and less suitable for the characterization of clays. Claystones, per definition, feature grain sizes below the common $\mathrm{CT}$ resolution (in range of $1-2 \mu \mathrm{m}$ ) and also grain densities, i.e. absorption characteristics, which result in very challenging segmentation procedures. Although not all features can be resolved, $\mu$-CT was extensively used to improve the understanding of clays in sediments (oil industry), in soil science, and as barrier functions in repository systems for high-level radioactive waste (HLRW). The oil industry is particularly interested in 


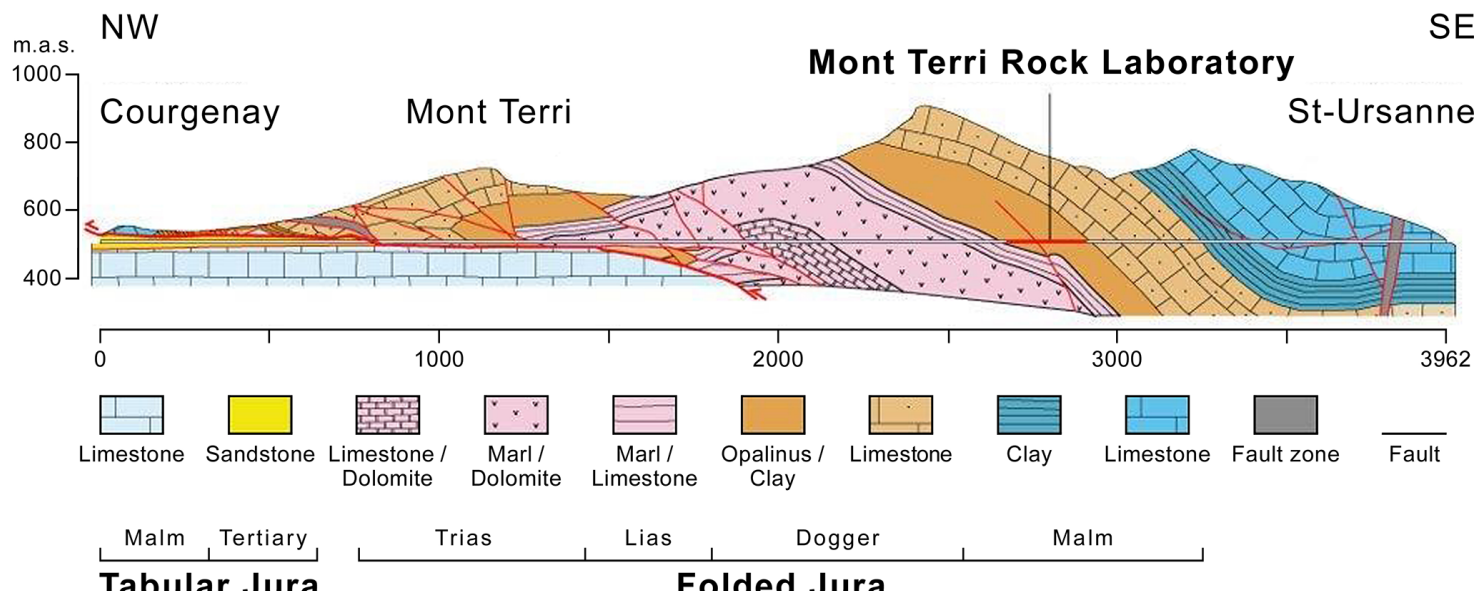

Figure 1. Stratigraphic cross section and location of the Mont Terri underground rock laboratory (URL). Figure modified after Freivogel and Hugenberger (2003).

porosity, permeability, and fluid flow in general. An overview of CT application in the oil industry and for soils is provided by Heijs et al. (1995) and Akin and Kovscek (2003). By using a medical CT, Ashi (1997) analysed texture and density of marine clays, whereas Yang et al. (2010) used CT data to support logging operations. For soils, Naveed et al. (2012) used CT to investigate the importance of macropores for the convective fluid flow. The influence of cations on pores of soils is discussed by Marchuk et al. (2013).

In HLRW research $\mu$-CT was used to investigate the wetting of clay pellets and for the assessment of homogeneity after wetting (van Geet et al., 2005), relations of mechanical properties and microstructure (Bésuelle et al., 2006; You et al., 2010), engineering properties such as deformation (Nakano et al., 2010; Mukonoki et al., 2014), and to visualize anisotropy of deformation and the excavated damage zone (You and Li, 2012). Keller et al. (2013) used a set of different methods (STEM, FIB, and $\mu$-CT) which allowed the "characterization of the pore structure in the fine-grained clay matrix at different levels of detail" of the Opalinus Clay (OPA). The OPA is particularly interesting because it will be the host rock and hence the main barrier for the Swiss repository for HLRW.

The Mont Terri underground rock laboratory (URL), where the investigated samples originate from, is located in the folded Jura in the Swiss Alps (Thury and Bossart, 1999; Heitzmann and Bossart, 2001). It is situated around $300 \mathrm{~m}$ in the underground and is accessed via one of the safety tunnels of the Mont Terri tunnel on the Trans-Jura motorway (Fig. 1). The rocks consist of hard limestones and dolomites and some soft marls and argillaceous rocks (claystone). These rocks have been formed in marine environments of different depths and coastal proximity.

The URL is located in the OPA, which is a mainly marly claystone with differing proportions of sand and carbonates.
In the OPA, two different facies can be distinguished. The clay-rich facies is referred to as "shaly facies" and hence distinguished from the "sandy facies". To resolve differences of both facies, nanotomography was used (Keller et al., 2013). Micro-computed tomography is not suitable to resolve all microstructural features of clays (micro and mesopore range) but rather useful to characterize the macroporescale, which is relevant for visualizing the crack distribution, advective fluid flow, and material heterogeneity, such as micro-bedding.

Especially in the field of geomechanical investigations, it is essential to get information about the mineral composition and microstructure - before and after mechanical tests. All these parameters have to be characterized to be able to increase the understanding of deformation processes. While the porosity and microfabric of tectonically undeformed OPA (Houben et al., 2013; Keller et al., 2011; Wenk et al., 2008) and naturally deformed OPA (Laurich et al., 2014) have been intensively studied, little is known of the microstructure and deformation mechanisms in experimentally deformed OPA.

In this study we present the investigations of an experimentally deformed OPA. The aim is the visualization of the shear failure in various scales to get more information about the deformation process. A sufficient understanding of the deformation process is necessary for the long-term safety case analysis for HLRW repositories. Figure 2 showcases the general workflow and the main idea for the investigation of the OPA with a consequent multiple-scale (scale-down) approach. 


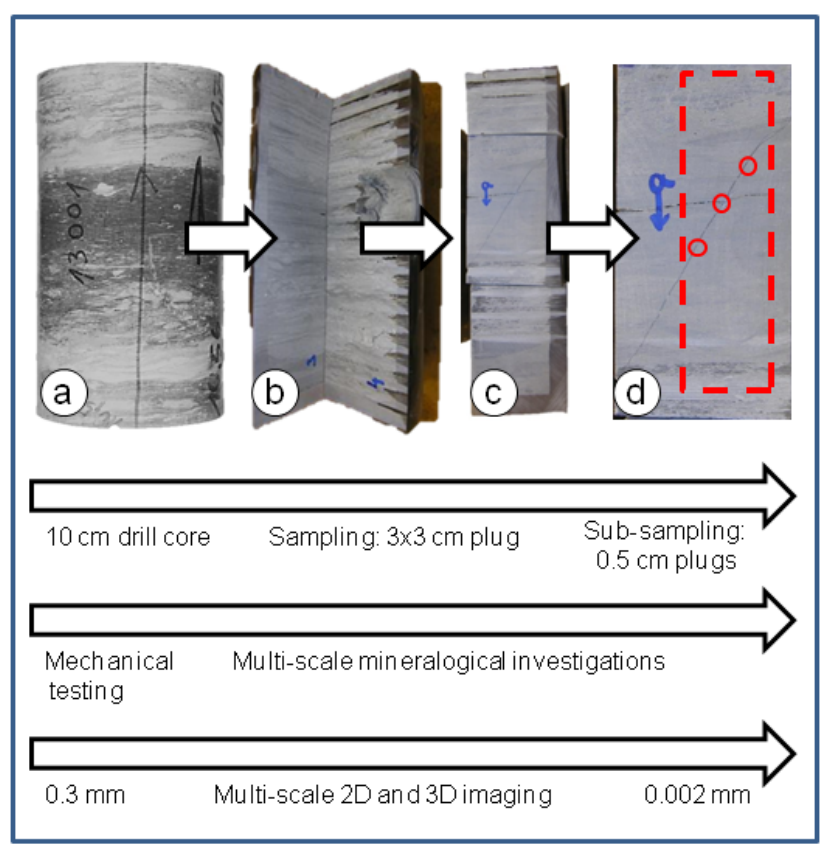

Figure 2. Generalized workflow for the multiple-scale investigations of the Opalinus Clay: from mechanical testing and imaging of the $10 \mathrm{~cm}$ drill core (a), to subsampled plugs for mineralogical and higher-resolution imaging (b and c), to small-scale samples (d) for high-resolution and specific region of interest investigations (red area: subsampling locations).

\section{Material and methods}

\subsection{Sample material}

The investigated specimen (file $13001=$ sample ID, drilling BLT-A6 = drilling ID) derives from the Mont Terri URL, St. Ursanne, Switzerland, and belongs to the sandy facies of the OPA (Fig. 3). The original core sample has a diameter of $100 \mathrm{~mm}$ and a length of $180 \mathrm{~mm}$. The drilling is orientated perpendicular to the bedding.

The sample has been sealed by a special vacuum bag to prevent the material from drying, in order to obtain the original saturation condition for the mechanical testing, and to prevent oxidation of pyrite and the subsequent formation of gypsum as best as possible. After the testing it was necessary to stabilize the sample with resin, since shear failure was fully developed. The specimen was then stepwise subsampled for X-ray CT and mineralogical and geochemical investigations on different scales (from $\mathrm{dm}$ to $\mathrm{mm}$ of sample size).

\subsection{Mechanical testing}

The claystone was tested by triaxial strength testing until a failure was developed (confining pressure $6 \mathrm{MPa}$, natural water content was preserved). The test was executed in deformation controlled mode with a deformation rate of

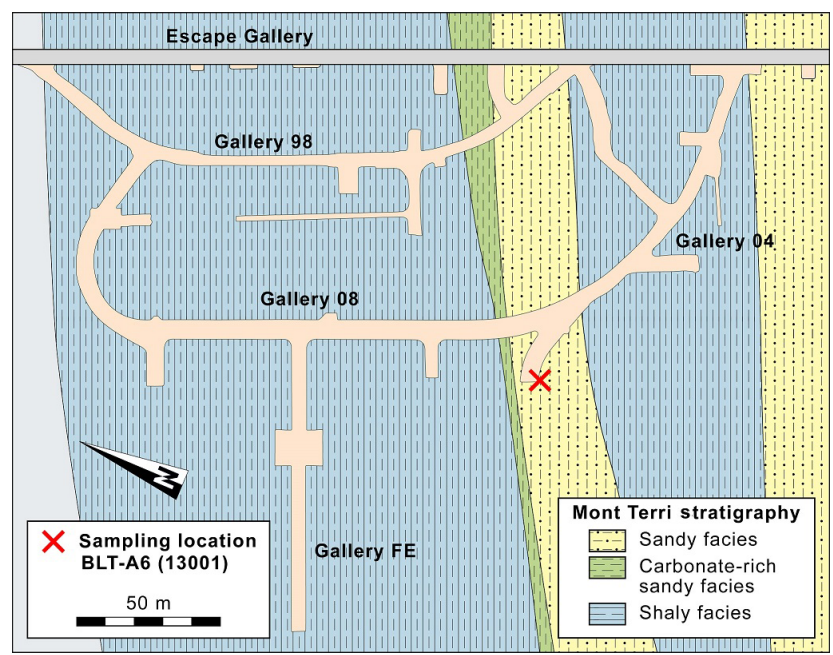

Figure 3. Schematic overview of the Mont Terri underground rock laboratory, showing the sampling location of the Opalinus Clay used for this study.

$\mathrm{d} \varepsilon / \mathrm{d} t=10^{-5} 1 \mathrm{~s}^{-1}$ and carried out under undrained condition (Gräsle and Plischke, 2010). After the mechanical testing the core was embedded in a resin to stabilize the specimen.

\subsection{Mineralogical and geochemical investigations}

XRD pattern were recorded using a PANalytical X'Pert PRO MPD $\Theta-\Theta$ diffractometer $(\mathrm{Cu}-\mathrm{K} \alpha$ radiation generated at $40 \mathrm{kV}$ and $30 \mathrm{~mA}$ ), equipped with a variable divergence slit (20 mm irradiated length), primary and secondary soller, Scientific X'Celerator detector (active length $0.59^{\circ}$ ), and a sample changer (sample diameter $28 \mathrm{~mm}$ ). The samples were investigated from 2 to $85^{\circ} 2 \Theta$ with a step size of $0.0167^{\circ} 2 \Theta$ and a measuring time of $10 \mathrm{~s}$ per step. For specimen preparation the top loading technique was used.

For XRF analysis of powdered samples, a PANalytical Axios spectrometer was used (ALMELO, the Netherlands). Samples were prepared by mixing with a flux material (lithium metaborate Spectroflux, flux no. 100A, Alfa Aesar) and melting into glass beads. The beads were analysed by wavelength-dispersive XRF. To determine loss on ignition (LOI), $1000 \mathrm{mg}$ of the sample material was heated to $1030^{\circ} \mathrm{C}$ for $10 \mathrm{~min}$.

The organic carbon content was measured with a LECO CS-444-Analysator after dissolution of the carbonates. Carbonates have been removed by treating the samples several times at $80^{\circ} \mathrm{C}$ with $\mathrm{HCl}$ solution until no further gas evolution could be observed. Samples of 170-180 mg of the dried material were used to measure the total carbon (TC) content. Total inorganic carbon was calculated by the difference of TC-TOC (total organic carbon). The samples were heated in the device to $1800-2000^{\circ} \mathrm{C}$ in an oxygen atmosphere and the $\mathrm{CO}_{2}$ was detected by an infrared detector. The device was 

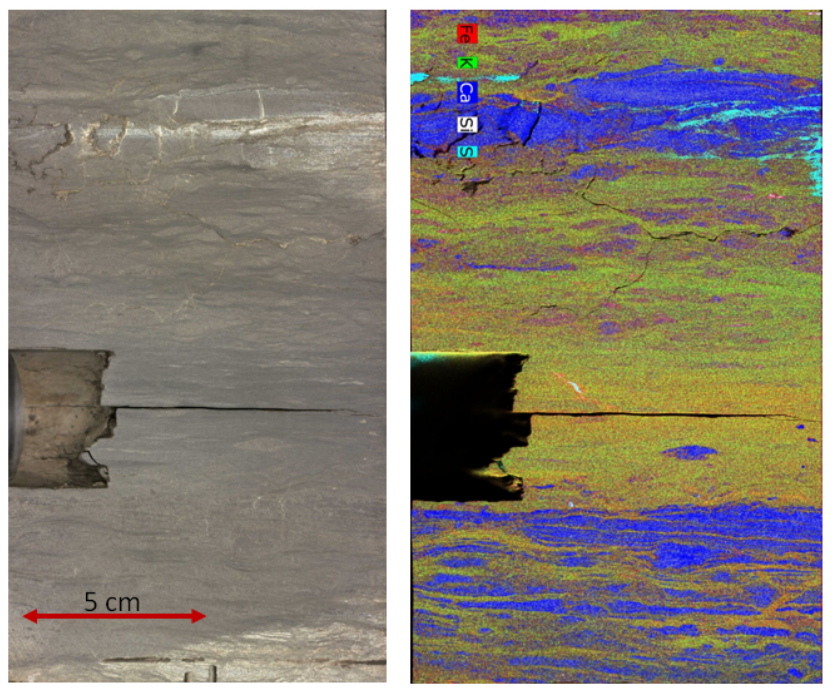

Figure 4. Results of the 2-D mineralogical mapping on the large core sample $(10 \mathrm{~cm})$.

built by LECO (3000 Lake Avenue, St. Joseph, Michigan 49085, USA).

The cation exchange capacity (CEC) was measured using the Cu-triethylenetetramine method (Meier and Kahr, 1999).

Both the smoothed drill core section $(21 \mathrm{~m} \times 18 \mathrm{~mm})$ and the three polished core heads $(\varnothing 5 \mathrm{~mm})$ were analysed for element distribution patterns by an energy-dispersive X-Ray fluorescence spectrometer, the EDXRF microscope M4 Tornado from Bruker Nano. The instrument is equipped with an Rh-tube generating a polychromatic beam, focused by a poly-capillary lens to a spot of a diameter of $17 \mu \mathrm{m}$ and two Xflash silicon drift detectors (SDDs). The takeoff angle for the tube in the moving direction and the detectors is $51^{\circ}$, and the arrangement of the detectors to the tube is in 90 and $270^{\circ}$ respectively. Measuring time was $2 \mathrm{~ms}$ at $50 \mathrm{kV}, 600 \mu \mathrm{A}$ and no filters were applied. The stepsize for the overview was $25 \mu \mathrm{m}$ and for the core heads $5 \mu \mathrm{m}$. False colour evaluation was performed by using the M4 Tornado software esprit.

The polished three drill core heads were investigated with an environmental scanning electron microscope (ESEM, type FEI Quanta 600 FEG) coupled with an energy dispersive X-ray (EDX) detector (two Xflash SDDs, Bruker Nano). Measurement conditions were $25 \mathrm{kV}$, approximately $200 \mu \mathrm{A}$, $4 \mu \mathrm{m}$ spot size, 19 times magnification at $11.4 \mathrm{~mm}$ working distance, and 2 min acquisition time.

\subsection{X-ray CT}

The OPA sample was first scanned with the speed|scan CT 64 located at the GE facility in Ahrensburg (Germany). Based upon a medical CT system, the CT 64 consists of a dust-protected radiation protection cabinet with an integrated, rotating ring-shaped scanning device (gantry) and sample transport system for moving components through the scan ring. The system may accommodate samples of up to $900 \mathrm{~mm}$ in length and $500 \mathrm{~mm}$ in diameter. The CT datasets are automatically generated in the so-called helix scan mode with a high-performance rotating anode X-ray tube and a 64channel multi-line detector rotating around the sample. Its unique technique allows an overall cycle time of typically 1 min per inspected sample (Ambos et al., 2014). Limitation of this type of equipment is the spatial resolution with typical 0.25 to $1 \mathrm{~mm}$. Nevertheless, due to the very high power of the X-ray tube $(72 \mathrm{~kW})$, different mineral phases can be very distinctively observed. The scan was recorded with $140 \mathrm{kV}$ and $140 \mathrm{~mA}$ within $13 \mathrm{~s}$ at a spatial resolution of $312 \mu \mathrm{m}$.

Second, a CT scan of the same sample was recorded with the v|tome|xL300 system at the GE facility in Wunstorf (Germany). For technical applications one main goal is the detection of failures at smallest dimension possible. This approach led to the development of tubes with a small focal spot to enable sharp images at high magnifications. One side effect of this is that the tube power is hereby limited. The only way to get enough information on the detector is to increase the scan time, typically from $30 \mathrm{~min}$ to $2 \mathrm{~h}$. In practice this delivers a resolution of approximately $60 \mu \mathrm{m}$ for a $10 \mathrm{~cm}$ core diameter, which is a factor of 5 to 10 better compared to "medical" CT scanners or such as the speed scan CT. Accordingly, the differentiation of mineral phases is significantly worse than for the high power system as described before. The scan parameters were $270 \mathrm{kV}$ and $0.3 \mathrm{~mA}$ and the scan duration was $145 \mathrm{~min}$. With this system a spatial resolution of $57.5 \mu \mathrm{m}$ has been achieved.

For smaller cores ( 1 to $10 \mathrm{~cm}$ ) this type of scanning device is still suitable, but when we get down in sample size to the $\mathrm{mm}$ range and thus want to achieve a resolution of a few microns there is a need to use so-called nanofocus tubes with a focal spot size below $1 \mu \mathrm{m}$. For the hereby described studies on $3 \mathrm{~mm}$ plugs a nanotom $\mathrm{m}$ system (GE Measurement \& Control, phoenix|x-ray) was used. For the $3 \mathrm{~cm} \times 3 \mathrm{~cm}$ plug and for the smallest samples which feature a diameter of 3 to $4 \mathrm{~mm}$, a spatial resolution of $2.8 \mu \mathrm{m}$ has been achieved.

\section{Results}

\subsection{Mineralogical and geochemical composition}

The aim of the present study was to investigate crack formation which could be related to microstructural features or mineralogical heterogeneities (fine bedding, fossil shells, etc.). The bulk sample is dominated by quartz and carbonates which is typical for the sandy facies of the OPA (Kaufhold et al., 2013; Siegesmund et al., 2013). Amongst the carbonates, calcite was most abundant. In addition, kutnohorite was found, which can be confounded with dolomite because of similar XRD reflections. The existence of traces of dolomite in addition to calcite and kutnohorite cannot be ruled out. Siderite is present as trace mineral. Muscovite 

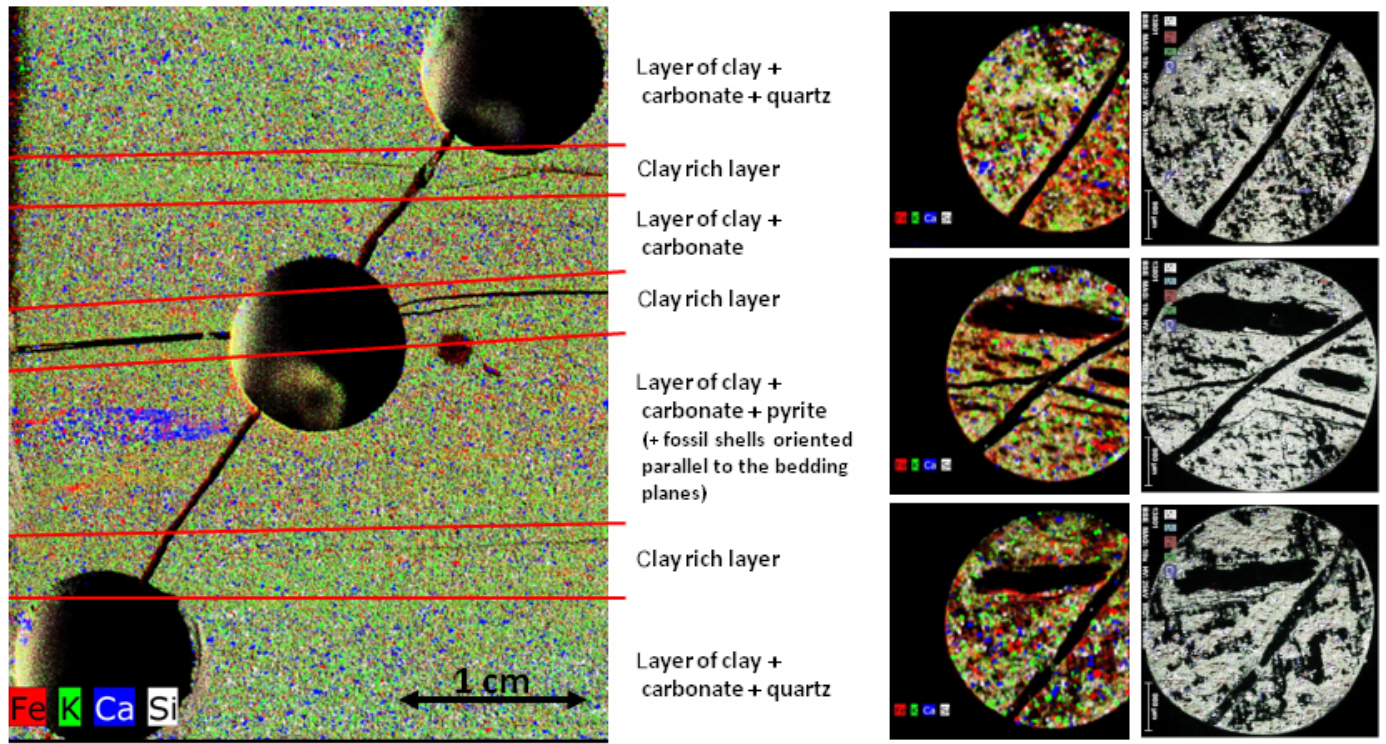

Figure 5. Results of the 2-D mineralogical and geochemical mapping on the small samples.

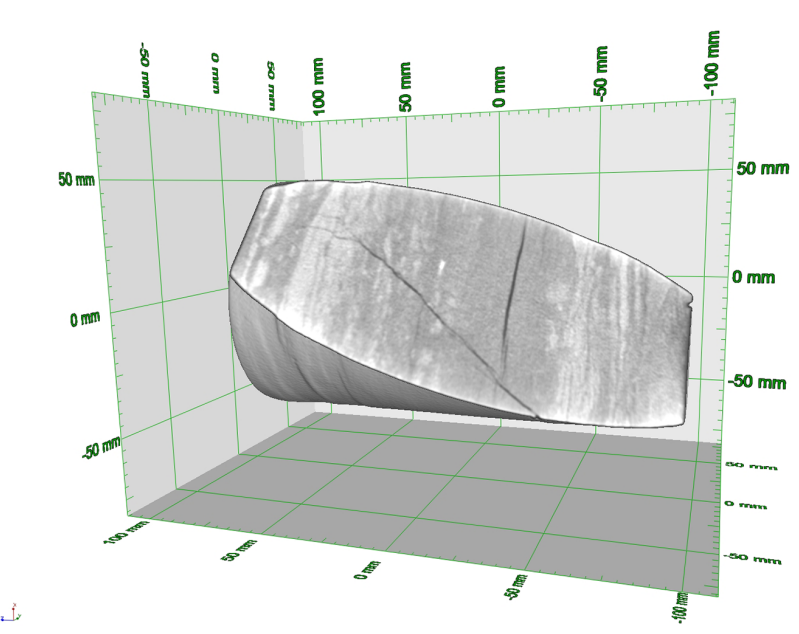

Figure 6. Partial 3-D view of the speed scan CT result. Within the virtual core, the layered structure (due to changes in the mineralogical composition) and two main cracks can be observed.

and illite could not be distinguished because of similar XRD reflections. Therefore, the presence of muscovite in addition to illite/smectite is possible. The CEC accounts for $7 \mathrm{meq} 100 \mathrm{~g}^{-1}$ pointing towards the presence of less than 10 mass-\% smectitic layers, which are predominately in illite/smectite mixed-layer minerals. Minor amounts of kaolinite, feldspar, and pyrite were also found. Using LECO elemental analysis 0.6 mass-\% of organic material was found. Assuming an average C-content of carbonate minerals of about 12 mass- $\%$ results in slightly more than 40 mass- $\%$ carbonates and 0.9 mass- $\%$ of sulfur corresponds to almost
2 mass-\% pyrite. This composition is in accordance with Kaufhold et al. (2013) and Siegesmund et al. (2013).

Therefore, the heterogeneity was investigated by $\mu$-XRF and scanning electron microscope (SEM). First the crossing of two cracks was investigated with respect to the mineral indicator elements $\mathrm{Si}, \mathrm{Ca}, \mathrm{Fe}$, and $\mathrm{K}$. Si represents quartz, $\mathrm{Ca}$ can be mostly found in carbonates, Fe dominates in pyrite and/or Fe-oxyhydroxides, and $\mathrm{K}$ indicates clay-rich layers because it can be mostly found in illite/smectite mixed-layer minerals, being the main clay mineral of the OPA. Results are depicted in Fig. 4. The XRF scanner results reveal the heterogeneities of the sample in the relevant scale with a resolution of a few $\mu \mathrm{m}$. The bedding, horizontal in the image, is reflected by a few millimetre thick clay layers (green) with more carbonatic layers in between. A centimetre-scaled region was found at the lower left section of the image, which could be a fossil, e.g. a shell fragment. However, this microstructure feature could not be related to the cracks.

Therefore, magnification was increased (Fig. 5). In these small sections of about $5 \mathrm{~mm}$, bedding features could not be detected anymore. Instead a few 50-100 $\mu$ m thick bands of either carbonates (blue) or clays (green) could be observed with a significant angle compared to bedding. Assuming that these small lineaments were no XRF artefacts, it can be supposed that a crack started to form there. This interpretation, however, only represents one option. As an alternative, crack formation may also coincide with material heterogeneities such as bedding features. Observations presented here do not allow for an unambiguous conclusion because the crack apparently formed outside the investigated area. The location from where tension relief observable as crack formation started is assumed to be outside the investigated area. Hence it can only be assumed that the small lineaments observed 

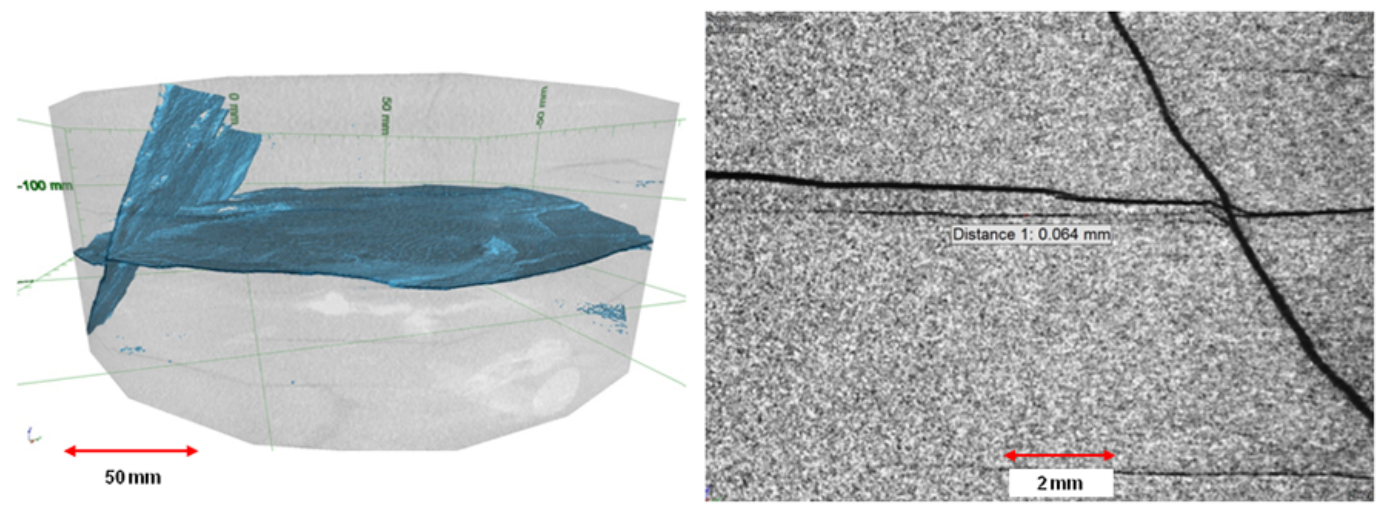

Figure 7. The main fractures have been segmented (left-hand side) and visualized in a transparent 3-D view. Besides the two major cracks, numerous tiny cracks can be detected. The fracture width can be measured down to approximately $60 \mu \mathrm{m}$.
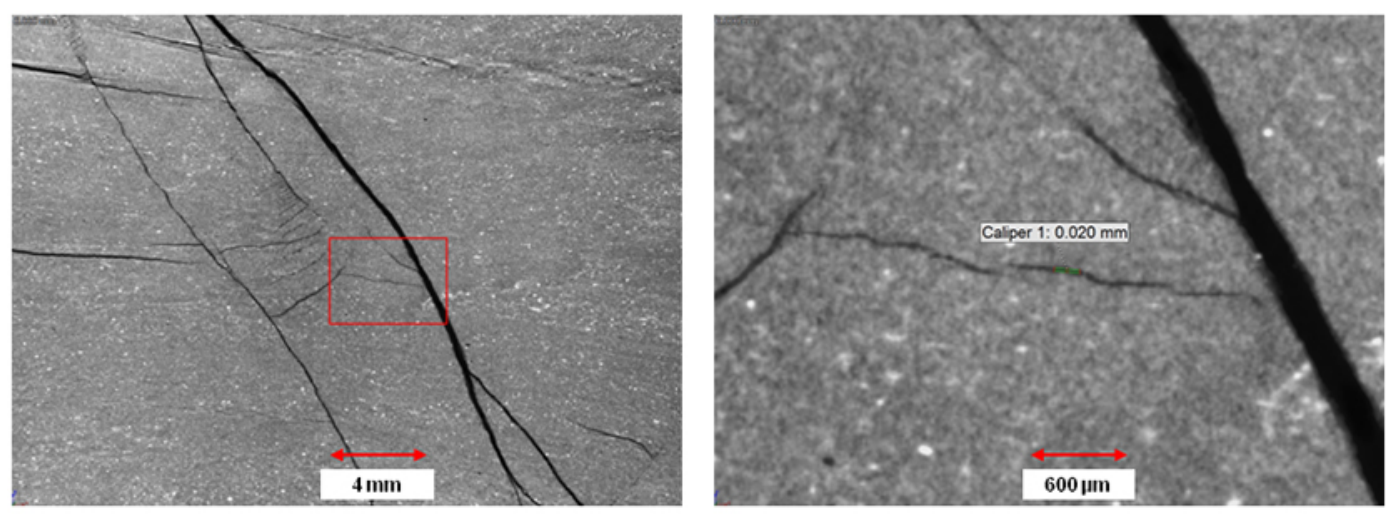

Figure 8. Many small-scale details of the mineralogical composition are now visible, as well as numerous small fractures. The red area is magnified on the right-hand side. Here, a small fracture is shown, which has an approximate aperture of about $20 \mu \mathrm{m}$.

both with the XRF scanner and with the SEM could be the starting point for crack formation.

\subsection{Large-scale and high-speed X-ray CT}

The CT results of the speed|scan CT 64 show good contrast resolution due to its high tube power (up to $72 \mathrm{~kW}$ ). Layering, i.e. changes in the mineralogical composition of the core, can be easily detected based on slightly changing density (see Fig. 6). The clay-rich areas are characterized by darker grey values (e.g. middle section of Fig. 6), while carbonatic regions are indicated by higher, i.e. brighter grey values. Layering features can be qualitatively observed in about the millimetre scale. Cracks and pores can be spatially resolved down to $0.5 \mathrm{~mm}$. For this core, two main fractures can be observed: a horizontal crack (fracture A), which is probably caused by de-hydration (so-called disking) of the core, and a shear crack caused by the laboratory mechanical testing. Interestingly, the shear fracture is located within the clay-rich area of the OPA sample. The starting point is right at the border between clay-rich and carbonatic zones (right-hand side of Fig. 6). Additionally, the fracture ends in a carbonatic re- gion (left-hand side of Fig. 6) and seems to fan out within that layer (also see video file 3 in the Supplement). The 3-D dataset can be virtually sliced in any direction to emphasize the specific layering or location of the crack system.

\subsection{Large-scale and high-resolution X-ray CT}

Compared to the faster device explained in the preceding paragraph, the CT results of the $\mathrm{v} \mid$ tome $\mid \mathrm{xL} 300$ show much better spatial resolution (down to approximately $60 \mu \mathrm{m}$ for $10 \mathrm{~cm}$ sample width). As the highest power of this system is $0.5 \mathrm{~kW}$, the phase contrast is not as high but still sufficient to detect larger zones of different densities. In contrast, the fractures are much better resolved ( 5 times better resolution) and the delicate network can be nicely visualized (Fig. 7) and studied more in detail. The effective fracture size for segmentation is in range of the achieved voxel resolution. Segmentation was performed in the central part of the sample, where the large horizontal crack is intersected by the diagonal-oriented crack system. Additionally, many small cracks could be observed, in most cases also horizontally oriented cracks, which also might be related to disking 

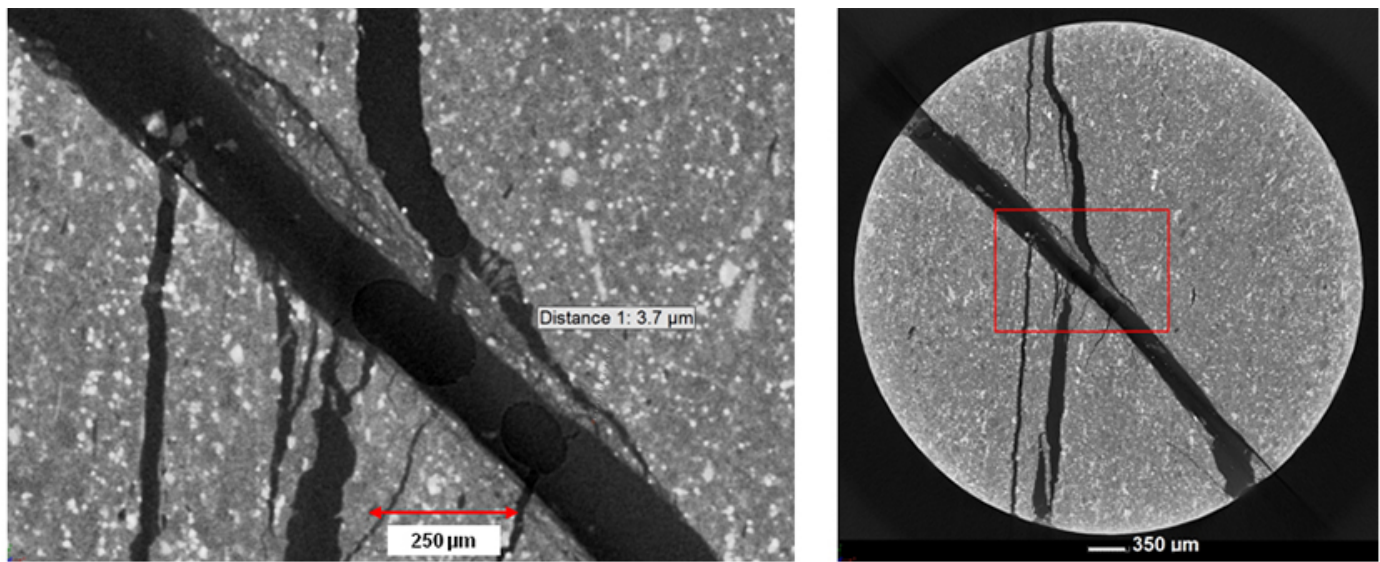

Figure 9. For the high-resolution dataset, many small cracking features can be observed. The magnified area marked by the red box is of special interest, since indications for a mylonitic zone can be found where the disking and shear fracture intersect.
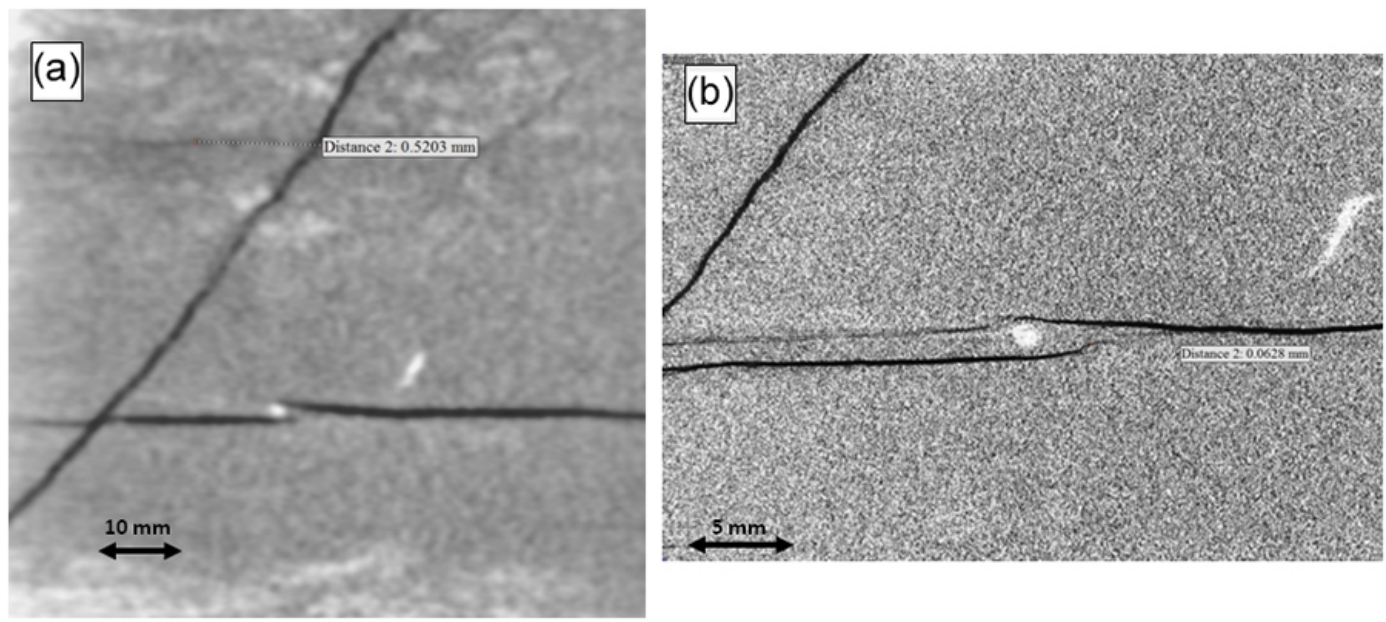

Figure 10. Direct comparison of both coarse-resolution scans with different techniques. Either enhanced phase contrast or spatial resolution can be derived. Hence, both techniques should be used complementarily.

effects. Interestingly, a zone of higher fracture density, or at least of higher density due to the lower grey values of that region, is located near the intersection of the two main fractures (Fig. 7, right-hand side). Consequently, this area has been chosen for subsampling and 2-D and 3-D investigation with higher resolution.

\subsection{Small-scale and high-resolution X-ray CT}

In order to achieve higher image resolution and to obtain good image quality, it is mandatory to downsize the sample as a smaller voxel size can only be achieved by increasing the geometrical magnification for the hereby described CT systems. In a first step a $3 \mathrm{~cm} \times 3 \mathrm{~cm}$ sample has been cut out and a CT scan was performed on a nanotom $\mathrm{m}$ system with a voxel resolution of about $18 \mu \mathrm{m}$. The results (Fig. 8) show significant improvement in diversity of small details. Individual carbonate shells can easily be distinguished and the overall fracture pattern becomes more and more resolved. Accordingly, smaller shear fractures can be detected, which are oriented more or less parallel to the main shear crack (Fig. 8, left-hand side). The magnified view (Fig. 8, righthand side) reveals at least three types of cracks could be distinguished based on the improved resolution imaging. Long diagonal cracks which sometimes split up into several subparallel branches were observed. These are the shear fractures constituting the shear failure plane. Secondly, some cracks following bedding plane features were observed. They may have formed by tensile failure. Finally, a system of small stacked cracks orientated more or less perpendicular to the large shear fractures could be observed. They may have formed later than the large shear fractures as they are truncated by the shear fractures. Generally, shearing normal to the main shear failure plane is expected to be almost negligible. Therefore, these stacked cracks probably formed by tensile failure. 
Table 1. Comparison of sample size and image resolution related fracture detection and geometrical fracture analysis results for the two main cracks observed.

\begin{tabular}{lrrrr}
\hline & & & \multicolumn{2}{c}{ Average crack aperture $(\mu \mathrm{m})$} \\
\cline { 4 - 5 } $\begin{array}{l}\text { Investigated } \\
\text { core volume }\left(\mathrm{mm}^{3}\right)\end{array}$ & $\begin{array}{r}\text { Voxel resolution } \\
(\mu \mathrm{m})\end{array}$ & $\begin{array}{r}\text { No. of cracks } \\
\text { detected }\end{array}$ & $\begin{array}{r}\text { Fracture A } \\
(\text { shear crack) }\end{array}$ & $\begin{array}{r}\text { Fracture B } \\
(\text { discing crack) }\end{array}$ \\
\hline $100^{3}$ & 312.5 & 3 & 990 & 1300 \\
$100^{3}$ & 57.5 & 15 & 393 & 364 \\
$30^{3}$ & 17.8 & 47 & 185 & 237 \\
$3^{3}$ & 2.8 & 107 & 182 & 228 \\
\hline
\end{tabular}
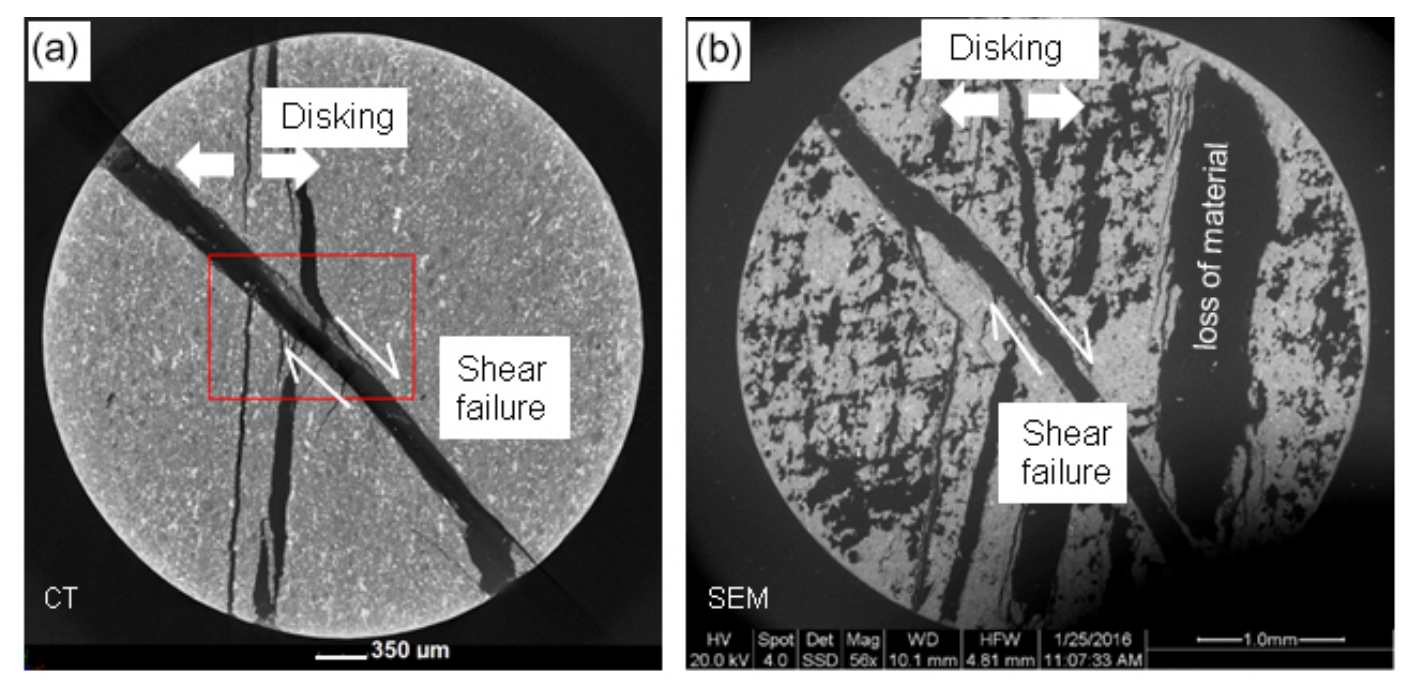

Figure 11. Sample overview: (a) X-ray CT image of a single layer; (b) SEM image of the polished surface.

For even smaller scale, micro-plugs were drilled with diameter of about $3 \mathrm{~mm}$ and scanned on the same system with a voxel resolution of approximately $2-3 \mu \mathrm{m}$. For this high resolution single grains can be observed as well as microcracks and small meso-pores (Fig. 9). Though no specific correlation between fracture occurrence and mineralogy can be observed, a small zone around that point, where the shear and disking fracture intersect each other, is of very special interest. This area can be characterized as a so-called mylonitic zone; i.e. an area with many small fractures and cracks where particles have been rearranged on the fracture surface. As far as literature research reveals, this seems to be the first reported CT dataset of such a zone. For more details, this sample has been used for the micro-scale mineralogical and microstructure investigations to get more evidence for this special feature.

\subsection{Multi-scale comparison of CT results}

For the investigation of the OPA material, a consequent scaledown approach has been used. Due to the different 3-D imaging scales, quantification of sample features (here the cracks and fractures) is challenging and may lead to differ- ent results. Table 1 highlights the number of detected cracks and fractures for the different (sub)samples and according (sub)volumes, as well as the average aperture of the two main fractures in relationship to the sample size and to the derived imaging resolution. The cracks and fractures have been segmented manually and semi-automatically from the 3-D CT datasets by using the AVIZO Fire software suite. Whereas the coarse-resolution scans show good results for a first mineralogical and textural sample characterization, details on the fracture development in particular cannot be revealed (Fig. 10).

Accordingly, subsampling the OPA material stepwise greatly increases the information of the fracture network. Hence, the total number of cracks detected increased by a factor of almost 36 . If the result is upscaled to the large core size, this would be a factor as high as 100 to 150 . Additionally, the existence of smaller disking as well as of smaller shear fractures has been showcased in the previous sections. As a matter of fact, the evaluation of the two main fractures on different scales leads to very different results. For the large core, fracture apertures are greatly overestimated ( 3 to 6 times, related to scanning resolution) due to partial volume effects and - of course - the effective segmentation 

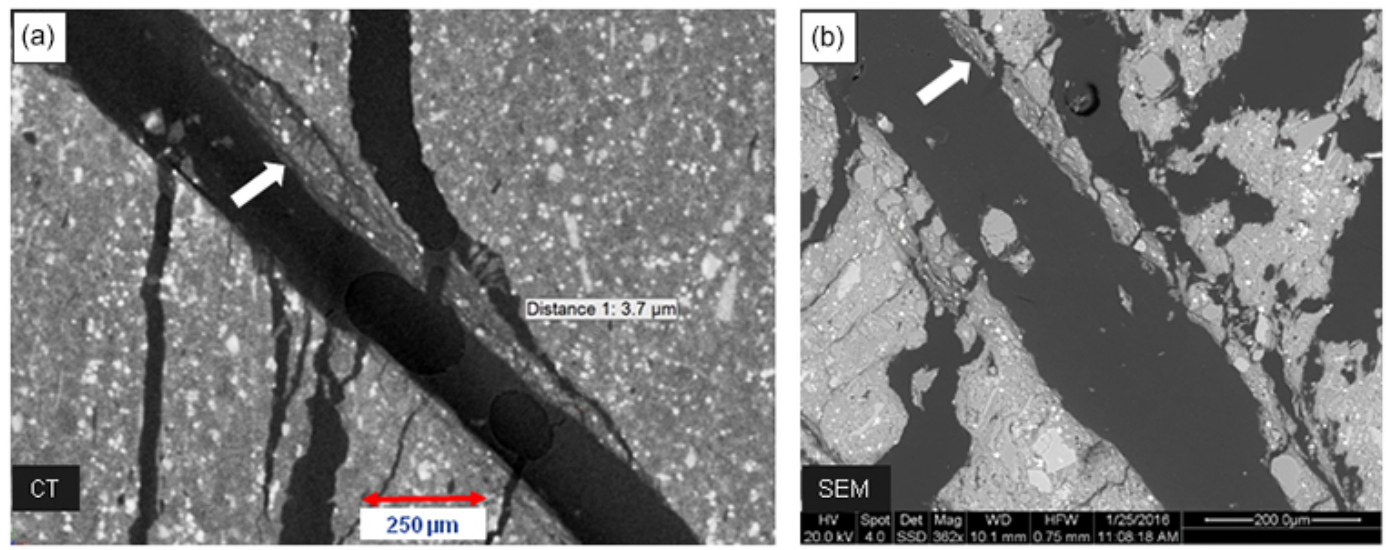

Figure 12. Magnified view of the shear failure from the X-ray CT image (a) and of the SEM image (b).
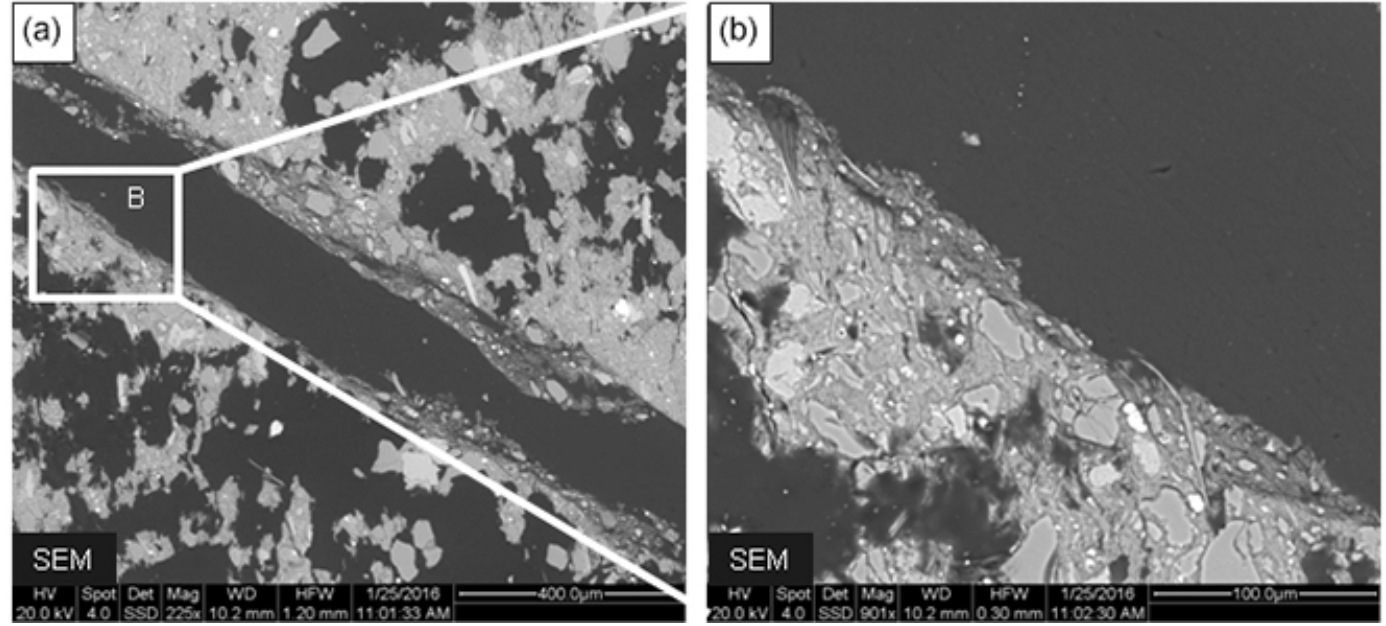

Figure 13. Very-high-resolution close-up of the mylonitic zone located in the shear failure area. It can be clearly observed how the particles have been pulled apart from the original matrix material and rearranged near the surface.

resolution. Results of the small and micro-samples are almost equal for the main crack evaluation. Nevertheless, the number of detected cracks still increases by a factor of about 2. Features such as the observed mylonitic zone can be indicated from the coarse scan data and evaluated in detail by the high-resolution image data.

In fact, the distinct scattering in the observed fracture apertures is related to three different effects: towards the image "quality", i.e. partial volume effects, towards the "effective segmentation resolution", and towards the fact that different parts of the volume have been used for this more qualitative approach, since volume registration was not successful due to the large image resolution difference.

\subsection{Microstructural investigation based on CT and SEM}

The microstructural investigation was carried out on microplugs. The plugs were first scanned with the high-resolution
$\mathrm{X}$-ray CT. For the SEM investigations (low vacuum) the samples were embedded in resin and the surface was polished. CT investigation provided complete 3-D information of the samples. One section of the 3-D scan is shown in Fig. 11a. The SEM image, of course, only represents the polished surface of the plug (Fig. 11b). Dark areas represent cracks filled with air (CT) or resin (SEM). Many more dark areas were observed by SEM which resulted from artefacts caused by sawing and polishing. Ideally an even surface is produced by polishing but the preparation of even surfaces of claystones is difficult. Depending on sample pretreatment (drying, wetting, etc.) claystones may at least partly disintegrate, resulting in a loss of material upon sawing and polishing. This explains why more dark areas were observed by SEM. Nevertheless, the main features to be investigated were observed by both techniques.

In both figures, shear failure and disking could be observed. Disking is assumed to be a relief failure in the bed- 
ding plane. It was already observed before the mechanical test was performed. The shear failure is overprinting disking and a material offset is clearly visible in both images. A closer look at the shear failure reveals more details (Fig. 12). In the CT image the shear failure and smaller microcracks parallel to bedding planes could be observed. Different minerals can be recognized, but a clear mineral boundary is not visible. Nevertheless on the top of the shear zone a darker zone was observed which may have resulted from a loosening of the material resulting in lower density.

The SEM image (Fig. 12b) has a higher resolution compared to the CT image. In principle, identical microstructure features were found with both methods. In combination with the 2-D SEM inspection, more indications can be observed in order to find out what happened in the mylonitic zone.

Close up SEM images (Fig. 13) prove that the claystone did not simply break as one would expect from broken glass. Such an appearance of the cracks points towards shear failure. Cracks induced by tensile failure would miss a mylonitic zone and hence be closer to the appearance of broken glass. Either before or throughout breaking a rearrangement of the particles and hence a destruction of the microstructure occurred. Platy particles, such as micas, have been rearranged (Fig. 13b), which indicates plastic deformation. As a result a "micro-mylonitic" seam at both sides of the crack was observed. This phenomenon was already observed by Laurich et al. (2014) for naturally deformed OPA. They explain the occurrence of this mylonitic zone as a gouge zone. It is not clear whether the mylonitic zone formed just before breaking or formed by the relative movement of both sides of the crack. However, taking into account the amount of local deformation and particle dislocation required to form the mylonitic zone, a formation before breaking would be very difficult to explain. Nevertheless, it is a key finding that such a zone exists in artificially deformed OPA and that this zone has been observed both in 2-D and 3-D datasets.

\section{Conclusions}

For the long-term safety analysis of repositories for radioactive waste it is necessary to predict the mechanical behaviour of the host rock. The understanding of mechanical processes in argillaceous rocks is considerably less developed than that of other materials like salt rocks. Hence the investigations presented above, for microstructure analysis in various scales regarding mechanical failure, is important to develop our understanding of mechanical behaviour of clay stones.
The OPA material has been intensively studied by a variety of multiple-scale and nondestructive 3-D X-ray CT investigations, following a consequent scale-down approach to identify specific regions of interest. According to the mechanical experiment, it has been observed that the shear failure is located in a clay-rich area. Within the intersecting area of the two main fractures, a so-called mylonitic zone with a particle reduction was observed on the open shear failure using CT and SEM techniques. However, it is not known, until now, when and how this zone was developed. As far as the authors are aware, this is the first time that experimental deformation shows such a mylonitic zone.

Therefore it is necessary to investigate further mechanical loaded specimens under different conditions (water content and strain). These mechanical investigations should be monitored with nondestructive $\mathrm{X}$-ray $\mathrm{CT}$ investigations and in further step accompanied with subsampling and small-scale image investigations. Then we will have the possibility to get more information about the petrophysical processes behind the mylonitic zone. All these investigations can help us to develop our understanding of mechanical behaviour, which is an important part in the long-term safety analysis of potential hazardous waste disposal places.

\section{Data availability}

Since the showcased 3-D imaging data sets are very large, it is not appropriate to store them, for example, in a cloud repository. Hence, all imaging data sets, as well as OPA sample materials, are available upon personal request to the corresponding author. 


\section{Appendix A}

Table A1. Geochemical and mineralogical composition of the bulk sample.

\begin{tabular}{|c|c|c|c|c|c|}
\hline \multicolumn{2}{|c|}{ Mineral composition } & \multicolumn{4}{|l|}{$\mathrm{XRF}$} \\
\hline Quartz & & ++ & $\mathrm{SiO}_{2}$ & [mass-\%] & 49.8 \\
\hline Calcite & & ++ & $\mathrm{TiO}_{2}$ & [mass-\%] & 0.7 \\
\hline Mg-kutnohorite & & +- & $\mathrm{Al}_{2} \mathrm{O}_{3}$ & [mass- $\%]$ & 10.7 \\
\hline Muscovite/illite (ML) & & +- & $\mathrm{Fe}_{2} \mathrm{O}_{3}$ & [mass- $\%]$ & 5.1 \\
\hline Kaolinite & & +- & $\mathrm{MnO}$ & [mass-\%] & 0.1 \\
\hline Feldspar & & +- & $\mathrm{MgO}$ & [mass-\%] & 2.2 \\
\hline \multirow{4}{*}{\multicolumn{2}{|c|}{ Pyrite }} & +- & $\mathrm{CaO}$ & [mass-\%] & 12.2 \\
\hline & & & $\mathrm{Na}_{2} \mathrm{O}$ & [mass-\%] & 0.4 \\
\hline & & & $\mathrm{K}_{2} \mathrm{O}$ & [mass- $\%]$ & 1,9 \\
\hline & & & $\mathrm{P}_{2} \mathrm{O}_{5}$ & [mass-\%] & 0.3 \\
\hline \multicolumn{3}{|l|}{ LECO } & $\mathrm{SO}_{3}$ & [mass- $\%]$ & 1.2 \\
\hline $\mathrm{C}_{\text {total }}$ & [mass-\%] & 3.6 & LOI & [mass- $\%]$ & 15.4 \\
\hline $\mathrm{C}_{\text {org }}$ & [mass-\%] & 0.6 & & & \\
\hline $\mathrm{C}_{\text {inorg }}$ & [mass-\%] & 3.1 & Sum & [mass-\%] & 99.9 \\
\hline $\mathrm{S}_{\text {total }}$ & [mass-\%] & 0.9 & & & \\
\hline \multicolumn{6}{|l|}{ CEC } \\
\hline CEC & [meq $\left.100 \mathrm{~g}^{-1}\right]$ & 7 & & & \\
\hline
\end{tabular}




\section{Information about the Supplement}

Video 1: high-resolution video of the mylonitic zone. Video 2: high-resolution overview video of the intersect region of the two main fractures. Video 3: low-resolution video of the speed scan data of the $10 \mathrm{~cm}$ Opalinus core.

\section{The Supplement related to this article is available online at doi:10.5194/se-7-1171-2016-supplement.}

Acknowledgements. The authors would like to thank Cornelia Müller (LIAG) for the support with the $\mu$-CT imaging and dataset evaluation, Frieder Enzmann (University of Mainz) for filter operation support, as well as Dieter Rammlmair (BGR) for providing EDXRF and ESEM measuring time and experience. Furthermore, we would like to thank the reviewers, who helped to improve the quality of this paper.

Edited by: H. Steeb

Reviewed by: W. Graesle and one anonymous referee

\section{References}

Akin, S. and Kovscek, A. R.: Computed tomography in petroleum engineering research, Geological Society London Special Publications, 01/2003, 23-38, 2003.

Ambos, E., Brunke, O., Neuber, D., Lux, H., Besser, W., and Ziesemann, M.: Porosity and Dimensional 3-D Process Control, Fast Computed Tomography in High Pressure Die Casting, Materials Evaluation, 978-984, 2014.

Andrä, H., Combaret, N., Dvorkin, J., Glatt, E., Junehee, H., Kabel, M., Keehm, Y., Krzikalla, F., Lee, M., Madonna, C., Marsh, M., Mukerji, T., Saenger, E., Sain, R., Saxena, N., Ricker, S., Wiegmann, and Zhan, X.: Digital Rock Physics Benchmarks part II: Computing Effective Properties, Comput. Geosci., 43, 33-43, 2013.

Ashi, J.: Computed tomography scan image analysis of sediments, in: Proceedings of the ocean drilling program, scientific results, edited by: Shipley, T. H., Ogawa, Y., Blum, P., and Bahr, J. M., 156, 151-159, 1997.

Bésuelle, P., Viggiani, G., Lenoir, N., Desrues, J., and Bornert, M. : X-ray Micro CT for Studying Strain Localization in Clay Rocks under Triaxial Compression, in Advances in X-ray Tomography for Geomaterials, edited by: Desrues, J., Viggiani, G., and Bésuelle, P., ISTE, London, UK, doi:10.1002/9780470612187.ch2, 2006.

Brunke, O., Brockdorf, K., Drews, S., Müller, B., Donath, T., Herzen, J., and Beckmann, F.: Comparison between X-ray tubebased and synchrotron radiation-based $\mu \mathrm{CT}$, Developments in XRay Tomography VI, edited by: Stock, S. R., Proceedings of SPIE, Vol. 7078, 2008.

Freivogel, M. and Huggenberger, P.: Modellierung bilanzierter Profile im Gebiet Mont Terri, La Croix (Kanton Jura), in: Mont Terri Project, Geology, Paleohydrology and Stress Field of the Mont Terri Region, edited by: Heitzmann, P. and Tripet, J.-P., Reports of the Federal Office for Water and Geology (FOWG), Geology Series, 4, 7-44, 2003.
Gräsle, W. and Plischke, I.: Laboratory Testing (LT) experiment: mechanical behavior of Opalinus Clay, Final Report from Phases 6-14, Mont Terri Project, Technical Report TR 2009-07, Federal Institute for Geosciences and Natural Resources (BGR), Hanover, 2010.

Heijs, A. W. J., de Lange, J., Schoute, J. F. T., and Bouma, J.: Computed tomography as a tool for non-destructive analysis of flow patterns in macroporous clay soils, Geoderma, 64, 183-196, 1995.

Heitzmann, P. and Bossart, P.: Das Mont-Terri Projekt - Untersuchungen über den Opalinuston im internationalen Felslabor, Bulletin of Angewandte Geologie, 6, 183-197, 2001.

Houben, M. E., Desbois, G., and Urai, J. L.: Pore morphology and distribution in the shaly facies of Opalinus clay (Mont Terri, Switzerland): insights from representative 2-D BIBeSEM investigations on $\mathrm{mm}$ to $\mathrm{nm}$ scale, Appl. Clay Sci. 71, 82-97, doi:10.1016/j.clay.2012.11.006, 2013.

Kaufhold, A., Gräsle, W., Plischke, I., Dohrmann, R., and Siegesmund, S.: Influence of carbonate content and microfabrics on the failure strength of the sandy facies of the Opalinus Clay from Mont Terri (Underground Rock Laboratory), Eng. Geol., 156, 111-118, 2013.

Keller, L. M., Holzer, L., Wepf, R., and Gasser, P.: 3-D geometry and topology of pore pathways in Opalinus clay: implications for mass transport, Appl. Clay Sci. 52, 85-95, doi:10.1016/j.clay.2011.02.003, 2011.

Keller, M. K., Holzer, L., Schuetz, P., and Gasser, P.: Pore space relevant for gas permeability in Opalinus clay: Statistical analysis of homogeneity, percolation, and representative volume element, J. Geophys. Res.-Sol. Ea., 118, 2799-2812, doi:10.1002/jgrb.50228, 2013.

Laurich, B., Urai, J. L., Desbois, G., Vollmer, C., and Nussbaum, C.: Microstructural evolution of an incipient fault zone in Opalinus Clay: Insights from an optical and electron microscopic study of ion-beam polished samples from the Main Fault in the Mt-Terri Underground Research Laboratory, J. Struct. Geol., 67, 107-182, doi:10.1016/j.jsg.2014.07.014, 2014.

Marchuk, A., Rengasamy, P., McNeill, A., and Kumar, A.: Nature of the clay-bond affects soil structure as verified by X-ray computed tomography, Soil Res., 50, 638-644, 2013.

Meier, L. P. and Kahr, G.: Determination of the cation exchange capacity (CEC) of clay minerals using the complexes of Copper (II) ion with Triethylenetetramine and Tretraethylenepentamine, Clay. Clay Miner., 47, 386-388, 1999.

Mukonoki, T., Nakano, T., Otani, J., and Gourc, J. P.: Study of cracking process of clay barrier in landfill using X-ray CT, Appl. Clay Sci., 101, 558-566, doi:10.1016/j.clay.2014.09.019, 2014.

Nakano, T., Mukunoki, T., Otani, J., and Gourc, J. P.: Development of a Bending Test Apparatus for Quasi-Dynamical Evaluation of a Clayey Soil Using X-Ray CT Image Analysis. Advances in Computed Tomography for Geomaterials: GeoX 2010, edited by: Alshibli, K. A. and Reed, A. H., John Wiley \& Sons, Inc., Hoboken, NJ, USA, doi:10.1002/9781118557723.ch49, 2010.

Naveed, M., Moldrup, P., Artur, E., Wildenschild, D., Eden, M., Lamandé, M., Vogel, H.-J., and de Jonge, L. W.: Revealing the soil structure and functional macroporosity along a clay gradient using X-ray computed tomography, Soil Sci. Soc. Am. J., 77, 403-411, 2012. 
Schlüter, S., Leuther, F., Vogler, S., and Vogel, H.-J.: X-ray microtomography analysis of soil structure deformation caused by centrifugation, Solid Earth, 7, 129-140, doi:10.5194/se-7-129-2016, 2016.

Schmitt, M., Halisch, M., Müller, C., and Fernandes, C. P.: Classification and quantification of pore shapes in sandstone reservoir rocks with 3-D X-ray micro-computed tomography, Solid Earth, 7, 285-300, doi:10.5194/se-7-285-2016, 2016.

Siegesmund, S., Popp, T., Kaufhold, A., Dohrmann, R., Gräsle, W., Hinkes, R., Schulte-Kortnack, D.: Seismic and mechanical properties of Opalinus Clay: Comparison between sandy and shaly facies from Mont Terri (Switzerland), Environ. Earth Sci., 71, 3737-3749, 2014.

Thury, M. and Bossart, P.: The Mont Terri rock laboratory, a new international research project in a Mesozoic shale formation, in Switzerland, Eng. Geol., 52, 347-359, 1999.

van Geet, M., Volckaert, G., and Roels, S.: The use of microfocus $\mathrm{X}$-ray computed tomography in characterising the hydration of a clay pellet/powder mixture, Appl. Clay Sci., 29, 73-87, 2005.
Wenk, H.-R., Voltolini, M., Kern, H., Popp, T., and Mazurek, M.: Anisotropy in shale from Mont Terri, The Leading Edge, 27, 742-748, doi:10.1190/1.2944159, 2008.

Yang, S. L., Schjetne, K., and Kvalstad, T.: Application of X-ray computed tomography in marine clays, The Twentieth international offshore and polar engineering conference, 20-25 June 2010, Bejing, China, ISBN:978-1-880653-77-7, 493-500, 2010.

You, S. and Ji, H. G.: Characterization by X-ray computed tomography of the bedding planes influence on excavation damaged zone of a plastic clay, Rock Mechanics: Achievements and Ambitions, ISBN:978-0-415-62080-2, 245-248, 2012.

You, S., Labiouse, V., Vigne, L., Gastaldo, L., and Bernasconi, M.: Medium resolution X-ray computed tomography of hollow cylindrical samples of Boom clay, Rock mechanics in civil and environmental engineering, 755-758, 2010. 